\title{
Enhancement of $\beta$-xylosidase productivity in cellulase producing fungus Acremonium cellulolyticus
}

\author{
Machi Kanna', Shinichi Yano ${ }^{1 *}$, Hiroyuki Inoue ${ }^{1}$, Tatsuya Fujii' and Shigeki Sawayama ${ }^{1,2}$
}

\begin{abstract}
Enzymatic hydrolysis is one of the most important processes in bioethanol production from lignocellulosic biomass. Acremonium cellulolyticus is a filamentous fungus with high cellulase production but productivity of hemicellulase, especially $\beta$-xylosidase, is lower than other filamentous fungi. We identified $2.4 \mathrm{~Kb} \beta$-xylosidase gene in the A. cellulolyticus genome sequence information and it encoded 798 amino acids without introns. To enhance hemicellulase productivity in A. cellulolyticus, we transformed this fungus with the identified $\beta$-xylosidase gene driven by the cellobiohydrolase I (cbh1) promoter, using the protoplast-polyethyleneglycol (PEG) method, and obtained a transformant, YKX1. Hydrolysis rate of xylooligosaccharides was more than 50-fold higher using culture supernatant from YKX1 than that from the parental strain, Y-94. Total cellulase activity (measured by filter paper assay) in YKX1 was not affected by the cbh1 promoter used for expression of $\beta$-xylosidase, and induced by cellulose. Since YKX1 can produce larger amount of $\beta$-xylosidase without affecting cellulase productivity, it is considered to be beneficial for practical monosaccharide recoveries from lignocellulosic biomass.
\end{abstract}

Keywords: Hemicellulase, beta-xylosidase, Acremonium cellulolyticus, Transformation, Cellulase

\section{Introduction}

Ethanol produced from lignocellulosic biomass is a second-generation biofuel which does not compete with food resources (Sims et al. 2010) and is expected to be an alternative to gasoline that reduces dependence on fossil fuels. Bioethanol can be produced from lignocellulosic biomass via several processes; pretreatment, enzymatic hydrolysis, and fermentation. In these processes, effective enzymatic hydrolysis of cellulose and hemicellulose is the most important step. Therefore, we focused on the enzyme activities that catalyze the saccharification of cellulose and hemicellulose.

Cellulose is the primary component of lignocellulosic biomass. After cellulose, hemicellulose is the second most abundant component of the plant cell wall, and accounts for $20-30 \%$ of lignocellulosic biomass (Girio et al. 2010,). Glucuronoxylans (O-acetyl-4-O-methylglucuronoxylan)

\footnotetext{
* Correspondence: s-yano@aist.go.jp

1 Biomass Technology Research Center, National Institute of Advanced Industrial Science and Technology, 3-11-32 Kagamiyama, Higashi-Hiroshima, Hiroshima, 739-0046 Japan

Full list of author information is available at the end of the article
}

are the most abundant type of hemicellulose, and they make up $15-30 \%$ of the dry mass in hardwoods (Girio et al. 2010). Although conventional ethanol fermenting yeasts cannot utilize xylose, we have developed efficient xylosefermentable Saccharomyces cerevisiae strains (Matsushika et al., 2009). Hence, effective saccharification of xylan is practically important for attaining higher yields of monosaccharides.

Endo- $\beta$-1, 4-xylanase and $\beta$-xylosidase catalyze the production of xylooligosaccharides from xylan and xylose from xylooligosaccharides, respectively. $\beta$-xylosidase hydrolyzes the non-reducing end of xylooligosaccharides. Although purified $\beta$-xylosidase is commercially available, it is too costly for practical large-scale applications. It will be beneficial if cellulase-producing filamentous fungi also produce hemicellulase for efficient and cost-effective hydrolysis of lignocellulosic biomass.

The $\beta$-xylosidase genes have been sequenced and characterized from many species of filamentous fungi. xylA of Aspergillus oryzae (Kitamoto et al. 1999) and xyl I of Aureobasidium pullulans strain ATCC 20524 (Ohta et al. 2010) belong to the glycosyl hydrolase (GH)

\section{SpringerOpen ${ }^{\circ}$}

(C) 2011 Kanna et al; licensee Springer. This is an Open Access article distributed under the terms of the Creative Commons Attribution License (http://creativecommons.org/licenses/by/2.0), which permits unrestricted use, distribution, and reproduction in any medium, provided the original work is properly cited. 
3 family. $x y l B$ in $A$. oryzae belongs to the GH43 family (Suzuki et al. 2010). Based on amino acid sequence, Bxl1 of Trichoderma reesei RutC-30 (Margolles-Clark et al. 1996), $X \ln D$ of Aspergillus nidulans (Perez-Gonzalez et al. 1998), and Aspergillus niger (van Peij et al. 1997,) belong to the GH 3 family (Suzuki et al. 2010). Furthermore, heterologous expression of $x y l B$ of $A$. oryzae in Escherichia coli was more stable than endogenous $X y l B$ expression in $A$. oryzae (Suzuki et al. 2010) or heterologous expression of $x \ln D$ from $A$. niger strain ATCC 10864 in Aspergillus awamori, which has similar activity on 4-nitrophenyl- $\beta$-D-xyloopyranoside to $A$. niger $X \ln D$ (Selig et al. 2008).

Acremonium cellulolyticus is a cellulase-producing filamentours fungus isolated in Japan (Yamanobe et al., 1987). Repeated UV and/or nitrosoguanidine (NTG) mutagenesis of the wild strain Y-94 was used to enhance cellulase productivity, and strains with high cellulase productivity (TN, C-1, and CF-2612) have been selected. Although the productivity of cellulase is quite high in $A$. cellulolyticus, its hemicellulase production is not sufficient. Recently, we have sequenced the whole genome of A. cellulolyticus (unpublished data) and could deduce many genes for saccharifying enzymes. Although there are only a few reports of successful transformation in A. cellulolyticus, we could successfully obtain many transformants with protoplast- PEG method. Therefore, we tried to enhance $\beta$-xylosidase productivity of this fungus by introducing its $\beta$-xylosidase gene under strong promoter.

Among strains of A. cellulolyticus, CF-2612 has the highest cellulase productivity (Fang et al. 2009), but it underwent random mutagenesis and may have mutations at every site as well as cellulase related genes. And apparently random mutagenesis affected the growth rates of CF-2612 because it grows more slowly than other strains. Therefore, we used the wild type strain, Y-94, in our study.

\section{Materials and methods}

\section{Fungal strain and culture condition}

A. cellulolyticus Y-94 (FERM Number BP-5826) was cultured in $10 \mathrm{ml}$ of medium in $100 \mathrm{ml}$ flasks at $30^{\circ} \mathrm{C}$ with shaking at $200 \mathrm{rpm}$. The composition of the culture medium for $A$. cellulolyticus was described previously (Fang et al. 2009). Sampling was performed at 1, 3, and 7 days for analysis of gene expression using real-time PCR and/or enzyme activity. A. cellulolyticus strains were cultured in potato dextrose (PD) medium for cloning and transformation.

Measurement of the amount of ATP, $\beta$-xylosidase and $\beta$-mannosidase activity, and saccharification efficiency The amount of ATP measured based on fluorescence using a Rucifel-250 kit (Kikkoman, Tokyo Japan) and
Lumitester C-100 (Kikkoman) according to the manufacturers' instructions.

Activities for $\beta$-xylosidase and $\beta$-mannosidase were measured using $100 \mu \mathrm{l}$ of $10 \mathrm{mM}$ 4-nitrophenyl- $\beta$-Dxyloopyranoside (PNP-Xyl, Sigma, MO USA) or 4-nitrophenyl- $\beta$-D-mannopyranoside (PNP-Man, Sigma) as the substrates (final concentration is $1 \mathrm{mM}$ ), respectively. Fifty $\mu$ of enzymes were incubated with 1 $\mathrm{mM}$ PNP-Xyl or PNP-Man at $45^{\circ} \mathrm{C}$ for 10 minutes in $850 \mu \mathrm{l}$ of $50 \mathrm{mM}$ acetic acid buffer (pH.5). After 10 minutes, $500 \mu \mathrm{l}$ of $1 \mathrm{M} \mathrm{NaCO}_{3}$ was added. Because 4nitrophenol which will be generated from substrates by enzymatic hydrolysis is a chromogenic substance, enzyme activities were assayed by measuring absorbance at $420 \mathrm{~nm}$ by UV-2550 Spectrophotometer (Shimadzu, Kyoto, Japan). One unit of the enzyme activity is defined as the amount of enzyme that produces 1 $\mu$ mol of p-nitrophenol per minute. For analysis of saccharification efficiency, culture medium was centrifuged at 9,000 g for $10 \mathrm{~min}$ to collect the supernatant containing the secreted enzyme. Enzyme solutions were incubated at $45^{\circ} \mathrm{C}$ in $50 \mathrm{mM}$ acetic acid buffer with $4 \%$ xylooligosaccharides (Wako Pure Chemicals, Osaka JAPAN). The xylose concentration was measured using a high performance liquid chromatography system (JASCO, Tokyo, Japan), under the conditions described previously (Buaban et al. 2010).

\section{Cloning $\boldsymbol{\beta}$-xylosidase gene from A. cellulolyticus}

A putative $\beta$-xylosidase gene, bxy $3 A$, was identified in A. cellulolyticus genome sequence information using A. nidulans $x \ln D$ sequence as the query for a homology search. In silico molecular cloning (in silico biology, Yokohama Japan) which is a software for gene analysis was used for homology search. Augstus 2.2 http://augustus.gobics.de/ which is a program for eukaryotic genome sequence was used for the prediction of genes. The $\beta$-xylosidase coding region was amplified using $A$. cellulolyticus CF-2612 genomic DNA as the template, and the cellobiohydrolase I (cbh1) promoter was amplified from Y-94 genome. For the extraction of genomic DNA, cells cultured in PD medium were collected by centrifugation, and 3 volumes of TE $(10 \mathrm{mM}$ Tris- $\mathrm{HCl}, 1 \mathrm{mM}$ EDTA, pH 8.0) with $2 \%$ sodium dodecyl sulfate (SDS) were added to the cell pellet. The cell suspension was incubated at $50^{\circ} \mathrm{C}$ for $1 \mathrm{hr}$. Potassium acetate $(5 \mathrm{M})$ was added to the cell suspension at one-tenth of total volume, and this mixture was incubated on ice for $1 \mathrm{hr}$. The mixture was centrifuged at $13,000 \mathrm{~g}$ for $10 \mathrm{~min}$, and the supernatant was subjected to two rounds of phenol-chloroform treatment, and ethanol precipitation was performed to obtain genomic DNA. The DNA was incubated with RNaseA (Nippon gene, Toyama, Japan) at $37^{\circ} \mathrm{C}$ for $1 \mathrm{hr}$ to degrade contaminating RNA. 
To amplify $\beta$-xylosidase open reading frame from A. cellulolyticus DNA, the forward primer with engineered SpeI site (5'-GCACTAGTATGGTCTACACCACG) and the reverse primer with engineered KpnI site (5'-GCGGT ACCTCAATTAGAATCAGGC) were designed based on sequence from the $A$. cellulolyticus genome sequence information (unpublished data) using Augustus 2.2 software The promoter from the cellobiohydrolase I (cbh1) gene (GenBank Accession number; E39854) was amplified with the forward primer with an XhoI site (5'-GCCTCGAGAAGCTTGGAAGCT) and the reverse primer with a SpeI site (5'-TACCATGGCTGCACTAGTGTGTCGATTGCTT). The amplified fragment of the $c b h 1$ promoter was connected to $\beta$-xylosidase gene in frame, and incorporated into a shuttle vector pLD10 provided by Dr. $\mathrm{H}$. Corby Kistler (University of Minnesota, USA), and the resulting plasmid, pLcbX-1, was obtained. E. coli DH5 $\alpha$ cells (Takara Bio, Shiga, Japan) were used to maintain the plasmid.

\section{Transformation of $A$. cellulolyticus}

The parental strain, Y-94, was transformed using a slightly modified protoplast-PEG method (Fincham et al. 1989). An overnight culture of $A$. cellulolyticus was treated with in $10 \mathrm{mM} \mathrm{KH}_{2} \mathrm{PO}_{4}, 0.8 \mathrm{M} \mathrm{NaCl}$, and $0.2 \%$ Yatalase (Takara Bio) to prepare protoplasts. The protoplasts were washed with $0.8 \mathrm{M} \mathrm{NaCl}$ and suspended in Solution A (1.2 M Sorbitol, $10 \mathrm{mM}$ Tris- $\mathrm{HCl}, 10 \mathrm{mM}$ $\left.\mathrm{CaCl}_{2}\right)$. Plasmid $(10 \mu \mathrm{g})$ was added to the protoplast suspension, then $50 \mu \mathrm{l}$ of Solution B (40\% PEG4000, 10 $\mathrm{mM}$ Tris- $\mathrm{HCl}, 10 \mathrm{mM} \mathrm{CaCl} 2$ ) was added to the protoplast suspension, and the suspension was incubated on ice for $30 \mathrm{~min}$ and RT for $15 \mathrm{~min}$. Then, $8.5 \mathrm{ml}$ of solution A was added to the cell suspension to dilute Solution B. The protoplasts suspension was spread on YPSA plate (1\% Bacto yeast extract, $1 \%$ Bacto tryptone, $1 \mathrm{M}$ Sucrose, and $2 \%$ Agar) and incubated overnight at $30^{\circ} \mathrm{C}$. PD medium with $0.2 \%$ agar with $500 \mu \mathrm{g}$ hygromycin was piled on to the YPSA plate. A single colony was isolated 3 days after the addition of PD medium. To confirm the presence of hygromycin phosphotransferase (hph) gene, transformant was checked by PCR using the forward (5'-ATGCCTGAACTCACCGCGAC-3') and the reverse (5'-CTATTCCTTTGCCCTCGGAC-3') primers.

\section{Measurement of FPU, xylanase, and mannanase activities} The FPU activity assay described by Ghose (1987) was performed as a reference for cellulase activity. Whatman NO.1 filter paper (paper size; $1 \mathrm{~cm} \times 6 \mathrm{~cm}$, Whatman, Kent UK) was used as the substrate. Culture medium was centrifuged at 9,000 g for 10 min to collect the supernatant with the secreted enzyme. Enzyme solution in $1 \mathrm{ml}$ of $50 \mathrm{mM}$ citric acid buffer, pH4.8, was incubated with the substrate at $50^{\circ} \mathrm{C}$ for $60 \mathrm{~min}$. DNS solution (3 ml; 1\% 3, 5-dinitrosalycilic acid (Sigma), $1.2 \% \mathrm{NaOH}, 0.05 \%$ sodium sulfate, and $20 \%$ potassium sodium tartrate tetrahydrorate) was added to the enzyme solution, and the mixture was boiled for $5 \mathrm{~min}$, then the reaction mixture was put on ice. The amount of glucose was measured with the absorbance at $540 \mathrm{~nm}$ with UV-2550 Spectrophotometer as a reducing sugar.

For assay of xylanase and mannanase, 2\% birch-wood xylan (Sigma) or 1\% Konjac Glucomannan (Megazyme, Wicklow, Ireland) were used as substrates, respectively. The incubation time for enzymatic reaction was $30 \mathrm{~min}$ and activities were assayed according to the previously described method (Bailey et al. 1991).

\section{Measurement of gene expression by real-time PCR}

For analyzing expression of the $\beta$-xylosidase gene, we performed real-time PCR. RNA was extracted with Fast RNA Pro Red kit (MP biomedicals CA USA) at one day after starting the cultures. The extracted RNA was cleaned using the RNeasy mini kit (Qiagen, Hilden Germany). cDNA was prepared using the M-MLV reverse transcriptase (Takara Bio) and oligo (dT) 20 (Toyobo, Osaka Japan). Samples were labeled by iQ SYBR Green (Bio-Rad, CA USA). Primers used for real-time PCR were as follows: For $\beta$-xylosidase: 5'-TTCCCGGTTAG GGTTTGATG-3' (forward) and 5'-GGGACACCATTCACCGAGTT-3' (reverse), for cellobiohydrolase I: 5'-ACTGCCTCCTTCAGCAAACAC-3' (forward) and 5'-GGCGTAGTCGTCCCACAAA-3' (reverse), for $\beta$-actin (the internal control): 5'-CAACTGGGACGACATGGAGA-3' (forward) and 5'-GTTGGACTTGG GGTTGATGG-3' (reverse).

\section{Nucleotide sequence accession number}

The DDBJ accession number of $b x y 3 A$ sequence is AB613265.

\section{Results}

A putative $\beta$-xylosidase gene, $b x y 3 A$, was identified in $A$. cellulolyticus genome sequence information using the $A$. nidulans $x \ln D$ sequence as the query for a homology search. The size of the gene was $2.4-\mathrm{Kb}$ and it encoded 798 amino acids without introns. The amino acid sequence deduced from $b x y 3 A$ was aligned with other $\beta$-xylosidase sequences (data not shown). This protein had 74\% identity to T. reesei Bxl1 (Margolles-Clark et al. $1996)$ and $61 \%$ identity to A. nidulans XlnD (PerezGonzalez et al. 1998).

The Bxy3A expression construct is shown in Figure 1. The $c b h 1$ promoter was used to drive expression of the deduced bxy $3 A$ open reading frame. The $h p h$ gene coding region driven by the transient receptor potential (trp) $\mathrm{C}$ promoter was used as the selection marker. The plasmid, pLcbX-1, with the $B x y 3 A$ expression construct 


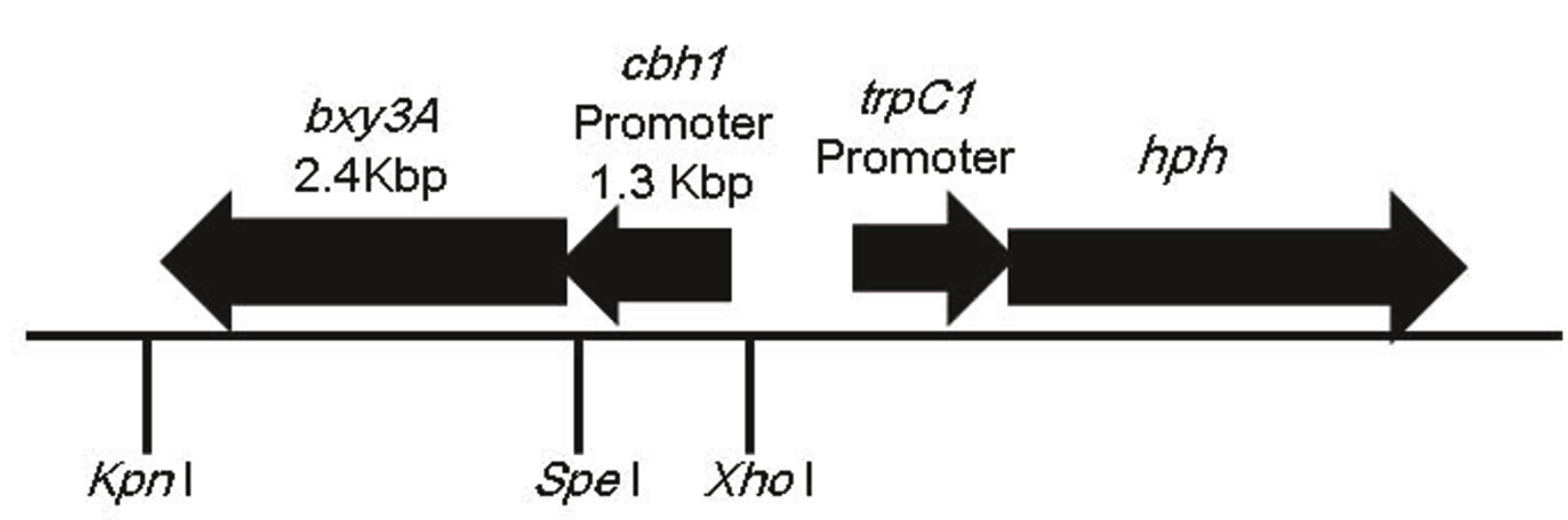

Figure 1 The structure of the expression cassette in transformation vector pLcbx-1. The deduced $\beta$-xylosidase gene was ligated at the indicated restriction site. TrpC; Transient receptor potential hph; hygromycin phosphotransferase

and the hph marker was transformed into A. cellulolyticusY-94 using the protoplast-PEG method.

We had transformation experiments in A. cellulolyticus with protoplast-PEG method using $h p h$ as the selection marker, and could obtain transformants. The mean value of transformation efficiency was $0.24 \times 10^{6}$ cells $^{-1}$. We have isolated a transformed colony with pLcbX-1on a YPSA plate containing $500 \mu \mathrm{g} / \mathrm{ml}$ hygromycin. The transformant, YKX1, could grow on PDA plates with $500 \mu \mathrm{g} / \mathrm{ml}$ hygromycin, and the presence of $h p h$ was confirmed by PCR from genomic DNA of the strain (data not shown). Growth rates were determined by measuring ATP concentration, because growth rates of filamentous fungi cannot be well assessed by measuring optical density. The growth of YKX1 gradually increased relative to that of Y-94 by 3 and 7 days after the start of the cultures, though growth rates were similar on the first day after the start of the cultures (Figure 2).

We measured $\beta$-xylosidase activity in YKX1 and Y-94 cultured in medium with cellulose as a sole carbon source, on days 1,3 and 7 . The $\beta$-xylosidase activity was markedly higher in YKX1 than in Y-94 (Figure 3). The amount of secreted protein in YKX1 was similar to that in Y-94 on all days (data not shown). To assess bxy3A gene expression in YKX1 and Y-94, we performed realtime PCR (Table 1). bxy3A expression was more than ten-fold higher in YKX1 than in Y-94 when the strains were grown in medium with cellulose. Although the expression of $c b h 1$ was slightly lower on average in YKX1 than in Y-94, FPU values of Y-94 (1.27 \pm 0.14 $\mathrm{FPU} / \mathrm{ml})$ and $\mathrm{YKX}(1.13 \pm 0.15 \mathrm{FPU} / \mathrm{ml})$ were not significantly different. This fact suggests that the $c b h 1$ gene was not disrupted by homologous recombination. We analyzed the insertion position by the genome walking method (data not shown). The cbh1 was located at
HND05_CDS0018, but the transformation cassette was not inserted at either of this position (data not shown).

We also measured xylanase activity both in YKX1 and Y-94, and activity was similar in YKX1 and Y-94 on the third day of culture (Table 2). Furthermore, activities of other hydrolyzing enzymes i.e. $\beta$-mannanse and $\beta$-mannosidase were also similar in YKX1 and Y-94 (Table 2). We had experiments of xylooligosaccharides hydrolysis of the transformant. After $1 \mathrm{hr}$ incubation, YKX1 cultures had a higher xylose yield than did Y-94 cultures (Figure 4). After 48 hr, YKX1 cultures had xylose yield of $60 \%$ from xylooligosaccharides.

\section{Discussion}

In filamentous fungi, $\beta$-xylosidase of each species belongs to one of $3 \mathrm{GH}$ families, 3, 43, or 54 (Knob et al. 2010). The putative $\beta$-xylosidase gene in A. cellulolyticus, bxy3A, showed high homology to $\beta$-xylosidase of the GH 3 family, and Bxy3A shared a conserved motif with the GH 3 family.

In this study, to increase hemicellulase productivity, the $c b h 1$ promoter was used to drive overexpression of BXY3A. CBH1, which is one of major cellulase, cleaves cellulose at the non-reducing end and produces cellobiose. CBH1 protein accounts for about $60 \%$ of all secreted proteins in $T$. reesei. Therefore, the $c b h 1$ promoter is widely used as a promoter for overexpression of homologous or heterologous gene (Keränen and Penttilä 1995). However, expression cassettes containing the $c b h 1$ promoter might integrate at the $c b h 1$ loci by homologous recombination. Actually, it was reported that expression of $c b h 1$ was abolished by homologous recombination, pcbh1-gus in T. reesei PC-3-7 (Rahman et al. 2009). Moreover, the value of cellulase activity of Pcbh1-gus, in which uidA encoding $\beta$-glucuronidase is 


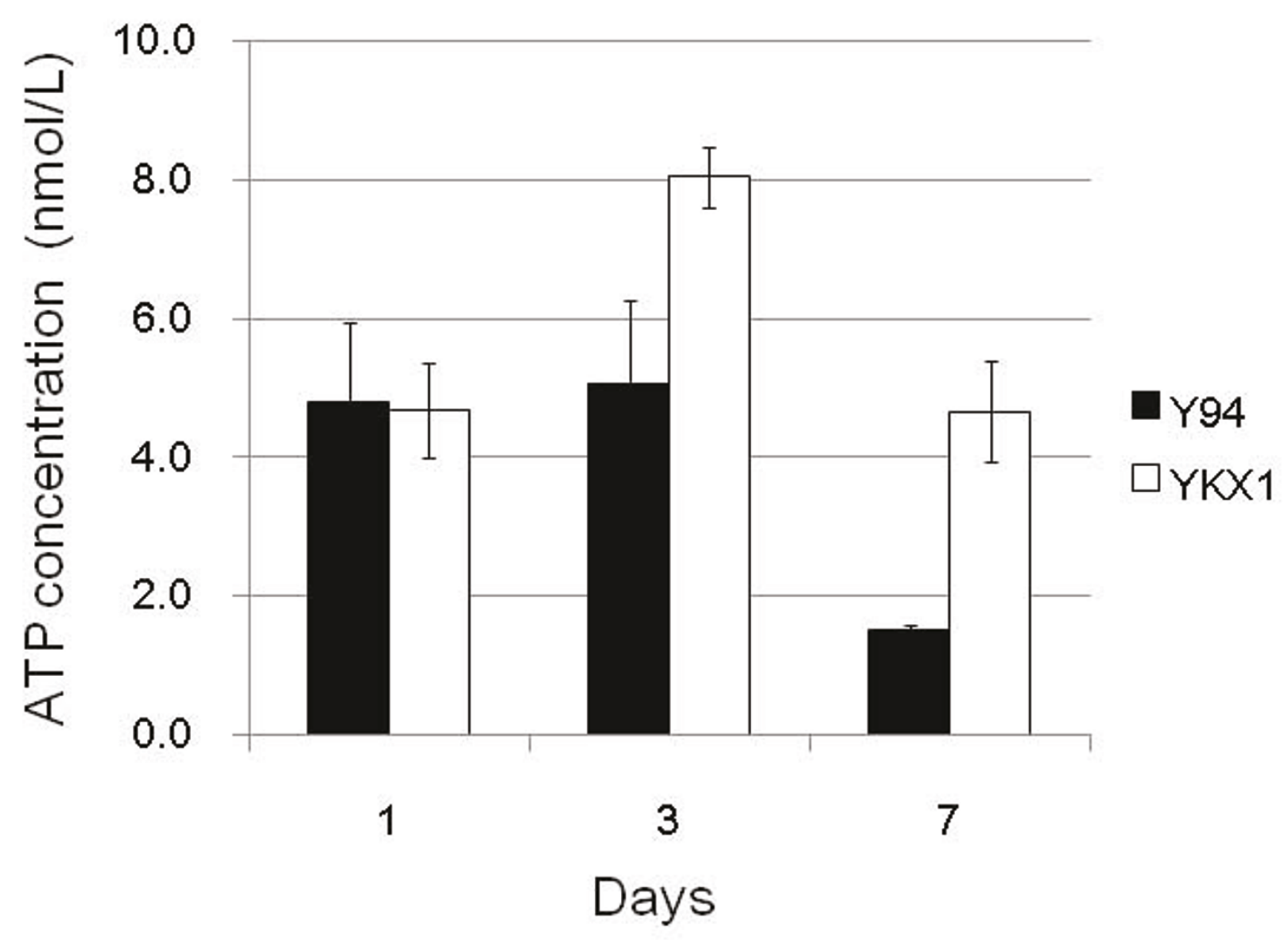

Figure 2 The amount of ATP as the indicator of fungal growth at 1, 3, and 7 days. Closed column; Y-94, Open column; YKX1. Standard deviations are calculated from triplicate experiments.

ligated between the $c b h 1$ promoter and the $c b h 1$ terminator, was half of that in wild type (Rahman et al. 2009). In this study, FPU activity of YKX1 was similar to that of Y-94. In most transformation experiments in filamentous fungi, a terminator is added downstream of the open reading frame. We did not ligated the terminator of $c b h 1$ at downstream of $b x y 3 A$. Therefore, the expression cassette was less likely to induce a double crossover. However, it is possible that a single crossover could have occurred at $c b h 1$ gene. Although $c b h 1$ gene of YKX1 was slightly lower than that of Y-94, expression cassette did not disrupt the original $c b h 1$ gene.

$\beta$-xylosidase gene in the integrated transformation cassette was expressed and the produced enzyme functioned. Xylosidase activity in YKX1 was higher than that in Y-94 grown in PD medium (data not shown), while activity of YKX1 was much higher than that of Y-94 in medium with $4 \%$ Solcaflock (Figure 3 ). Another potential problem with using the $c b h 1$ promoter was a possible titration effect; the cellulase genes may have bound most of the transcription factor, $x y r 1$, in $T$. reese $i$ (Stricker et al. 2006). In A. niger, $x \ln R$ which is an ortholog of $x y r 1$, induces expression of the cellulase gene (Stricker et al. 2008). In both cases, expression from the endogenous $c b h 1$ gene might decrease by an additional $c b h 1$ promoter due to competition for the transcription factor. However, we found that FPU activity of YKX1 was similar to Y-94, which suggests titration effect did not occur in YKX1.

We were also concerned that a titration effect might decrease expression from the endogenous $\beta$-xylosidase gene because $x y r 1$ induces $b x l 1$ and $x \ln R$ induces $x \ln D$ in $T$. reesei and $A$. niger, respectively (Stricker et al. 2006,, Stricker et al. 2008). It was difficult to determine whether the endogenous $\beta$-xylosidase was influenced by a titration effect because YKX1 was transformed with the open reading frame from the endogenous $\beta$-xylosidase gene. However, expression of $b x y 3 A$ driven by the cbh1 promoter in YKX1 was higher than expression of the endogenous $b x y 3 A$ in the parental strain (Table 1 ). 


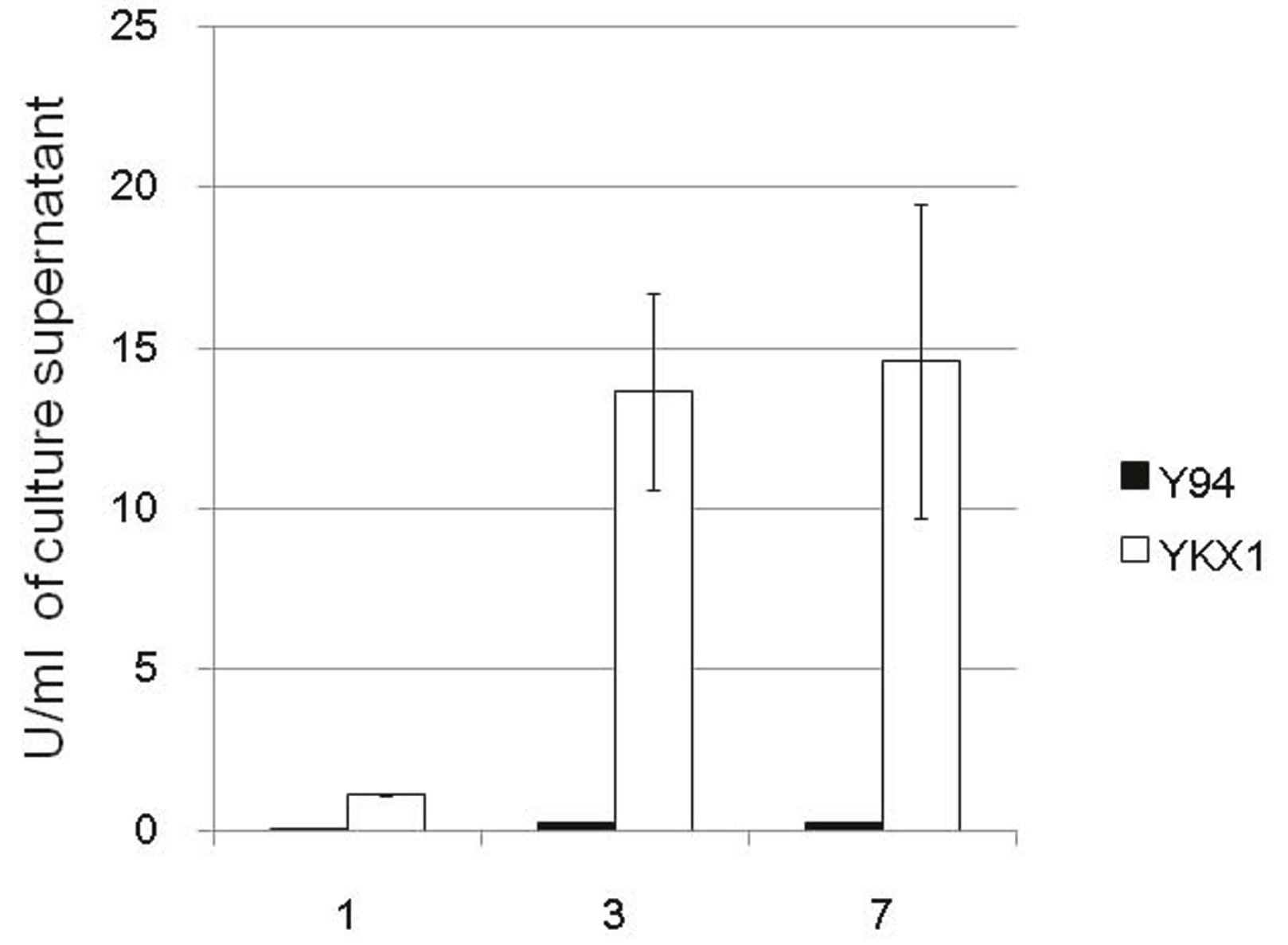

Incubation time (d)

Figure 3 Activity of $\beta$-xylosidase was measured 1, 3, and 7 days after culture grown in $\mathbf{4} \%$ solca flock. Closed column; Y-94, Open column; YKX1. Standard deviations are calculated from triplicate experiments.

Because there was no evidence of any titration effect in $\mathrm{YKX} 1$, it is appropriate to use the cbh1 promoter to enhance hemicellulase activity in the strain A. cellulolyticus Y-94.

Expression of the xylanolytic gene, $b x l 1$, is induced by xylobiose in T. reesei (Margolles-Clark et al. 1997). In $A$. nidluns, $\mathrm{D}$-xylose induces xylanolytic enzymes via the regulatory gene, $x \ln R$ (Tamayo et al. 2008).

Table 1 Gene expression in Y94 and YKX1 was analyzed one day after the cultures were started.

\begin{tabular}{lll}
\hline & Y94 & YKX1 \\
\hline$\beta$-xylosidase & $0.02 \pm 0.004$ & $3.3 \pm 0.509$ \\
Cellobiohydrolase I & $15.78 \pm 3.316^{*}$ & $11.16 \pm 2.321 *$
\end{tabular}

Number showed expression relative to an internal control (gene/ $\beta$-actin) *P $<0.01$
Although D-xylose and xylobiose can induce xylanolytic enzymes, another report indicates that the activity of $\beta$-xylosidase depends on the concentration of D-xylose in T. reesei (Mach-Aigner et al. 2010). $\beta$-xylosidase activity of YKX1 might have no effect in the presence of D-xylose because YKX1 used cbh1 promoter.

YKX1 grew faster than Y-94 in the same medium measured by ATP amount (Figure 2). In a previous

Table 2 Enzyme activity 3 days after the cultures were started.

\begin{tabular}{lcc}
\hline & Y94 (U/ml) & YKX1 (U/ml) \\
\hline$\beta$-xylanase & $56.68 \pm 4.13$ & $59.59 \pm 2.96$ \\
$\beta$-mannanase & $4.21 \pm 0.29$ & $3.76 \pm 0.21$ \\
$\beta$-mannnosidase & $0.0071 \pm 0.00042$ & $0.0063 \pm 0.00042$ \\
\hline
\end{tabular}




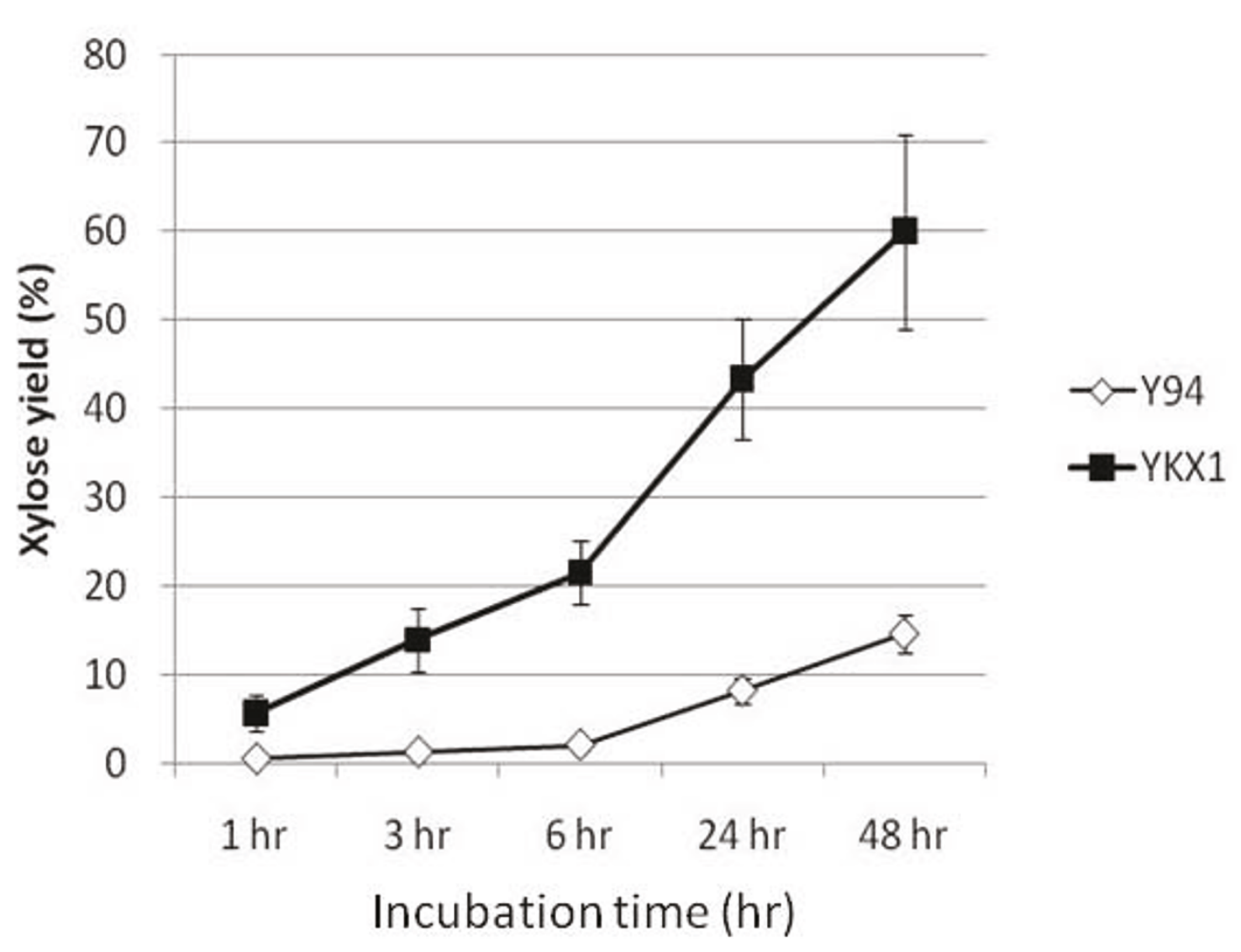

Figure 4 Xylose yields from saccharification of xylooligosaccharides. The enzyme solution was prepared from culture medium with $4 \%$ solca flock. Closed symbol; Y-94, Open symbol; YKX1 Standard deviations are calculated from triplicate experiments.

study, cellulase activity increased gradually as the amount of ATP decreased (Fang et al. 2009,). Similarly in YKX1, xylosidase activity was highest at 7 days, which was when ATP concentrations decreased. The behavior of the enzymatic activity was similar to other cellulolytic enzyme in this previous report (Fang et al. 2009) because the promoter used was from cellulolytic enzyme expression. Furthermore, the amount of ATP in YKX1 was higher than that in Y-94 at 3 and 7 days (Figure 2). In contrast, the values of cellulase activity in CF-2612 and C-1 are negatively correlated ATP concentrations (Fang et al. 2009). However, ATP levels in YKX1 were consistently high than those in Y-94.

Furthermore, the activities of other hemicellulolytic enzymes were similar in YKX1 and Y-94 (Table 2), indicating that the transformation was not affected by other hemicellulase. We generated a transformant of A. cellulolyticus that has higher $\beta$-xylosidase productivity than the parental strain without affecting cellulase or other hemicellulase productivity. We confirmed xylose yield improved by adding enzyme solution of YKX1, in saccharification experiments using rice straw (data not shown). Therefore, YKX1 should be useful for enzyme production in practical applications that convert both cellulose and xylan into fementable monosaccharides.

\section{Acknowledgements}

This work was supported by New Energy and Industrial Technology Development Organization (NEDO) of Japan. We would like to thank to Dr. Min-tian Gao for helpful discussion and Ms. Miyu Sumii and Ms. Reiko Yoshii for technical assistance.

\section{Author details}

'Biomass Technology Research Center, National Institute of Advanced Industrial Science and Technology, 3-11-32 Kagamiyama, Higashi-Hiroshima, Hiroshima, 739-0046 Japan ${ }^{2}$ Graduate School of Agriculture, Kyoto University, Kitashirakawa Oiwake-cho, Sakyo-ku, Kyoto, 606-8502, Japan

\section{Competing interests}

The authors declare that they have no competing interests.

Received: 9 May 2011 Accepted: 30 June 2011 Published: 30 June 2011

\section{References}

Bailey MJ, Biely P, Poutanen K (1992) Interlaboratory testing of methods for assay of xylanase activity. J Biotech 23:257-270

Buaban B, Inoue H, Yano S, Tanapongpipat S, Ruanglek V, Champreda V, Pichyangkura R, Rengpipat S, Eurwilaichitr L (2010) Bioethanol production 
from ball milled bagasse using an on-site produced fungal enzyme cocktail and xylose-fermenting Pichia stipitis. J Biosci Bioeng 110:18-25. doi:10.1016/ j.jbiosc.2009.12.003.

Fang X, Yano S, Inoue H, Sawayama S (2009) Strain improvement of Acremonium cellulolyticus for cellulase production by mutation. J Biosci Bioeng 107:256-261. doi:10.1016/j.jbiosc.2008.11.022.

Fincham J RS (1989) Transformation in Fungi. Microbiol reviews 53:148-170

Ghose TK (1987) Measurement of cellulase activities. Pure Appl Chem 59:257-268

Girio FM, Fonseca C, Carvalheiro F, Duarte LC, Marques S, Bogel-Łukasik R (2010) Hemicelluloses for fuel ethanol: A Review Bioresour Technol. 101:4775-4800. doi:10.1016/j.biortech.2010.01.088.

Keränen S, Penttilä (1995) Production of recombinant proteins in the filamentous fungus Trichoderma reesei. Curr Opin Biotech 6:534-537

Kistler HC, Benny U (1992) Autonomously replicating plasmids and chromosome rearrangement during transformation of Nectria haematococa. Gene $117: 81-89$

Kitamoto N, Yoshino S, Ohmiya K, Tsukagoshi N (1999) Sequence analysis overexpression, and antisense inhibition of a $\beta$-xylosidase gene, $x y / A$, from Aspergillus oryzae KBN616. Appl Environ Microbiol 65:20-24

Knob A, Terrasan CRF, Carmona EC (2010) $\beta$-Xylosidases from filamentous fungi: an overview World J Microbiol Biotech 26:389-407

Mach-Aigner AR, Pucher ME, Mach RL (2010) D-Xylose as a repressor or inducer of xylanase expression in Hypocrea jecorina (Trichoderma reesei). Appl Environ Microbiol 76:1770-1776

Margolles-Clark E, Tenkanen M, Nakari-SetäLä T, Penttilä M (1996) Cloning of genes encoding $\mathrm{a}$-L-arabinofuranosidase and $\beta$-xylosidase from Trichoderma reesei by expression in Saccharomyces cerevisiae. Appl Environ Microbiol 62:3840-3846

Margolles-Clark E, Ilmén M, Penttilä M (1997) Expression patterns of ten hemicellulase genes of the filamentous fungus Trichoderma reesei on various carbon sources. J Biotechnol 57:167-179

Matsushika A, Inoue H, Murakami K, Takimura O, Sawayama S (2009) Bioethanol production performance of five recombinant strains of laboratory and industrial xylose-fermenting Saccharomyces cerevisiae. Bioresour Technol 100:2392-2398

Ohta K, Fujimoto H, Fujii S, Wakiyama M (2010) Cell-associated $\beta$-xylosidase from Aureobasidium pullulans ATCC 20524: Purification, properties, and characterization of the encoding gene. J Biosci Bioeng 110:152-157

Pérez-González JA, van Peij NN ME, Bezoen A, MACcabe AP, Ramón D, de Graaff LH (1998) Molecular cloning and transcriptional regulation of the Aspergillus nidulans xlnD gene encoding a $\beta$-xylosidase. Appl Environ Microbiol 64:1412-1419

Rahman Z, Shida Y, Furukawa T, Suzuki Y, Okada H, Ogasawara W, Morikawa Y (2009) Evaluation and characterization of Trichoderma reesei cellulase and xylanase promoters. Appl Microbiol Biotechnol 82:899-908. doi:10.1007/ s00253-008-1841-3.

Selig MJ, Knoshaug EP, Decker SR, Baker JO, Himmel ME, Adney WS (2008) Heterologous Expression of Aspergillus niger $\beta$-D-Xylosidase $(X \ln D)$ : Characterization on lignocellulosic substrates. Appl Biochem Biotechnol 146:57-68

Sims REH, Mabee W, Saddler JN, Taylor M (2010) An overview of second generation biofuel technologies. Bioresour Technol 101:1570-1580

Stricker AR, Grosstessner-Hain K, Würleitner E, Mach RL (2006) Xyr1 (Xylanase Regulator 1) Regulates both the hydrolytic enzyme system and D-Xylose metabolism in Hypocrea jecorina. Eukaryot cell 5:2128-2137. doi:10.1128/ EC.00211-06.

Stricker AR, Mach RL, de Graaff LH (2008) Regulation of transcription of cellulases- and hemicellulases encoding genes in Aspergillus niger and Hypocrea jecorina (Trichoderma reesei). Appl Microbiol Biotechnol 78:211-220. doi:10.1007/s00253-007-1322-0.

Suzuki S, Fukuoka M, Ookuchi H, Sano M, Ozeki K, Nagayoshi E, Takii Y, Matsushita M, Tada S, Kusumoto K, Kashiwagi Y (2010) Characterization of Aspergillus oryzae glycoside hydrolase family $43 \beta$-xylosidase expressed in Escherichia coli. J Biosci Bioeng 109:115-117. doi:10.1016/j.jbiosc.2009.07.018.

Tamayo EN, Villanueva A, Hasper AA, de Graaff LH, Ramon D, Orejas M (2008) CreA mediates repression of the regulatory gene $x \ln R$ which controls the production of xylanolytic enzymes in Aspergillus nidulans. Fungal Genet Biol 45:984-993. doi:10.1016/j.fgb.2008.03.002.

van Peij, Brinkmann J, Vršanská M, Visser J, de Graaff LH (1997) $\beta$-Xylosidase activity, encoded by $x \ln D$, is essential for complete hydrolysis of xylan by
Aspergillus niger but not for induction of the xylanolytic enzyme spectrum. Eur J Biochem 245:164-173

Yamanobe T, Mitsuish Y, Takasaki Y (1987) Isolation of a cellulolytic enzyme producing microorganism. culture conditions and some properties of the enzymes. Agric Boil Chem 51:65-74

doi:10.1186/2191-0855-1-15

Cite this article as: Kanna et al.: Enhancement of $\beta$-xylosidase productivity in cellulase producing fungus Acremonium cellulolyticus. AMB Express 2011 1:15

\section{Submit your manuscript to a SpringerOpen ${ }^{\mathcal{O}}$ journal and benefit from:}

- Convenient online submission

- Rigorous peer review

- Immediate publication on acceptance

- Open access: articles freely available online

- High visibility within the field

- Retaining the copyright to your article

Submit your next manuscript at $\gg$ springeropen.com 